\title{
MUSEU VIRTUAL: O ENSINO DE ZOOLOGIA E A EDUCAÇÃO AMBIENTAL SOB UM OLHAR DIFERENTE, ANTES E DEPOIS DA COVID-19
}

\author{
Maria de los Angeles Perez Lizama1 \\ Felipe Zavaski $^{2}$ \\ Larissa Aparecida Wachholz ${ }^{3}$
}

Resumo: A tecnologia, cada vez mais inserida no cotidiano, permite que o mundo fique mais conectado. $O$ presente trabalho teve como objetivo relatar o processo de construção do museu virtual de Zoologia e História Natural, bem como a construção do saber pelos acadêmicos de Ciências Biológicas da Universidade Unicesumar na disciplina de Zoologia, analisando por meio de relatos de experiência dos acadêmicos envolvidos na construção do saber sobre Educação ambiental (EA), e os impactos que essa ferramenta pode gerar no contexto da pandemia de Covid-19. O museu proporcionou um espaço de pensamento crítico dos alunos sobre biodiversidade, preservação e educação ambiental (EA). Em tempos de isolamento social, exigido pela COVID-19, o museu possibilitou compartilhar experiências entre todos, tornando-o uma ferramenta importante nesse período.

Palavras-chave: Divulgação científica; Educação Ambiental; Zoologia; Ensino; Mídias digitais.

\footnotetext{
1 Universidade Cesumar/UNICESUMAR/ICETI. E-mail:maria.lizama@unicesumar.edu.br Link para o Lattes: http://lattes.cnpq.br/7827450324471754

2 Universidade Cesumar/UNICESUMAR. E-mail:felipe.zavaski@hotmail.com

Link para o Lattes: http://lattes.cnpq.br/7899860157756930

3Universidade Cesumar/UNICESUMAR/ICETI. E-mail: larissawachholz@hotmail.com Link para o Lattes: http://lattes.cnpq.br/9124079808082565
} 
Abstract: Technology, increasingly inserted in everyday life, allows the world to become more connected. The present work aimed to report the process of construction of the virtual museum of Zoology and Natural History, as well as the construction of knowledge by the biological sciences students of the Unicesumar University in the discipline of Zoology, analyzing through reports of experience of the academics involved in the construction of knowledge about Environmental Education (EA), and the impacts that this tool can generate in the context of the Covid-19 pandemic. The museum provided a critical thinking space for students on biodiversity, preservation, and environmental education (EA). In times of social isolation demanded by COVID-19, the museum made it possible to share experiences among all, making it an important tool in this period.

Keywords: Scientific dissemination; Environmental Education; Zoology; Teaching; Digital media.

\section{Introdução}

Cada vez mais presente no cotidiano, a tecnologia pode ser uma ferramenta significativa de conhecimento e de educação, como, por exemplo, nos museus virtuais. Preservar a história e a memória sempre foi um grande desafio, e é justamente por meio dessas que é possível fazer uma conexão entre passado, presente e futuro.

O termo museu vem das palavras gregas "Mousa" e "Moiseion", referidas ao templo das nove musas, ligadas a diferentes ramos das artes e das ciências, filhas de Zeus e Mnemosine, divindade da memória. Os primeiros museus, surgidos na Grécia antiga, eram jardins, bibliotecas e observatórios, considerados locais sagrados para estudos científicos e contemplação (CALDEIRA, 2005).

Atualmente, são espaços de cultura e história de uma civilização, bem como fontes de coleções científicas inestimáveis para a ciência (MUNIZ, 2020). Durante muito tempo, foram lugares em que as obras se encontravam para visitação pública e presencial. Por exemplo, um dos mais conhecidos museus em relação à arte, que se encontra em Paris, na França, o Museu do Louvre, alberga as maiores coleções do mundo. Em relação às ciências naturais, os museus de história natural de Nova lorque e Londres são referências mundiais em coleções. Em Londres, por exemplo, as coleções abrangem mais de 80 milhões de espécimes e 4,5 bilhões de anos de história da Terra (LONDON MUSEUM OF NATURAL HISTORY, 2020). Todavia, apesar da extrema relevância desses locais, apenas uma pequena parcela da população consegue visitá-los.

No Brasil existem mais de 1.200 museus. Contudo, ainda são incipientes, tendo em vista os 5.570 municípios existentes no país (IBGE, 2018). Essenciais para a preservação da história e da ciência brasileira, esses locais podem ser encontrados em diversas capitais, como a Pinacoteca de São 
Paulo e o Museu de Arte na cidade de São Paulo (MASP), o Museu Oscar Niemeyer (MON) em Curitiba, o Instituto Ricardo Brennand, de Recife, e Museu Imperial do Rio de Janeiro. Neste rol de espaços de renome, na ciência natural destacam-se o Museu de Ciências e Tecnologia da PUCRS, em Porto Alegre, o Museu Oceanográfico, no Rio Grande do Sul, e o Museu Nacional do Rio de Janeiro.

A grande questão é que ainda não são acessíveis a uma grande parcela da população, principalmente por se encontrarem nas capitais dos estados, visto que o acesso a esses locais demanda custos. Desta forma, os museus virtuais podem ser soluções importantes na aproximação da ciência e das artes à comunidade, tornando-os mais democráticos.

Em decorrência da pandemia do Coronavírus Disease-19 (COVID-19) e do período de isolamento social, cada vez mais os museus virtuais se tornam consideráveis instrumentos de preservação da memória cultural e científica de um povo, permitindo que o conhecimento seja levado a todo lugar. Esse conhecimento promove pensamento crítico ao cidadão, por meio de imagens científicas, didáticas e bem elaboradas, estimulando a formação de opinião acerca do meio em que se encontra. Em outras palavras, os museus virtuais podem ser grandes ferramentas de educação ambiental (EA) ao levar a ideia de pertencimento do indivíduo ao ambiente e a mudança de paradigmas.

Neste contexto, destaca-se ainda que esses espaços virtuais podem ser direcionados aos alunos de diferentes níveis escolares, como ferramenta de EA formal, bem como à comunidade externa, atendendo os propósitos da EA não-formal. Estes espaços podem levar a informação aos que acessam 0 seu conteúdo de forma mais rápida e eficaz (TEIXEIRA, 2014).

Diante disso, o presente trabalho teve como objetivo analisar, por meio de relatos de experiência dos acadêmicos envolvidos na construção de um museu virtual, os impactos que essa ferramenta pode gerar no contexto da pandemia de Covid-19.

\section{Procedimento metodológico}

O projeto de construção de um museu virtual foi desenvolvido na disciplina de Zoologia de Ciências Biológicas da Universidade Cesumar UNICESUMAR, durante o ano letivo de 2019. A sequência metodológica para a construção do conhecimento foi:

1. Pesquisa sobre os museus e sua importância para a preservação da fauna e do meio ambiente. Assim, tornou-se possível gerar conhecimento para as disciplinas das ciências biológicas e da saúde, além de proporcionar conteúdo para as escolas e a comunidade em geral;

2. Pesquisa dos temas a serem abordados no museu, como: Educação Ambiental e preservação ambiental, Biodiversidade, Zoologia dos 
vertebrados; Zoologia dos invertebrados, Técnicas utilizadas para manutenção dos materiais em laboratório (resinagem, taxidermia), entre outros;

3. Construção do acervo fotográfico do Laboratório de Zoologia por todos os alunos, para utilização nas matérias de divulgação científica do site e da exposição fotográfica;

4. Construção das matérias para divulgação no site e na exposição.

Para o desenvolvimento do projeto foram utilizadas diversas mídias digitais e recursos visuais, como: cartilhas, folders, banners, além de organismos em resinas, fotografias e animais taxidermizados. Parte desses materiais foi exposta na comemoração da Semana da Biologia, com a Exposição "Biologando", que apresentou também outros trabalhos confeccionados por alunos em várias disciplinas.

Com o intuito de analisar a experiência dos alunos, foi encaminhado um questionário, via plataforma Google forms, para que todos pudessem relatar, de forma espontânea, quais foram as impressões que tiveram ao participarem do processo de construção de conhecimento dentro da disciplina e como autores de material de divulgação científica para a comunidade. Todas as imagens utilizadas na pesquisa e na divulgação foram autorizadas pelos alunos por meio de um termo de concordância para publicação da imagem.

\section{Construção do saber por meio do Museu Virtual}

A disseminação de conhecimento por meios digitais é relativamente recente. A partir da década de 1990, as tecnologias digitais mudaram a forma como os jovens aprendem. Neste sentido, o conhecimento e a tecnologia não podem mais ser dissociados. Isto ocorre também com muitas Instituições e com os museus (HENRIQUES, 2018), mas não para todos. Muitos museus ainda não estão interligados à internet, o que dificulta 0 acesso das informações desses locais para a comunidade em geral.

Com o objetivo de produzir material didático sobre a fauna brasileira por meio da coleção zoológica existente no laboratório de zoologia da Universidade Cesumar, e tratar de temas como biodiversidade e cuidado com o Meio Ambiente por meio da educação ambiental de forma interdisciplinar, o museu virtual foi criado. Desta forma, tornou-se possível levar o conhecimento científico adquirido na disciplina para além da Instituição de Ensino Superior (IES), alcançando a comunidade externa.

Os alunos de Bacharelado da disciplina de Zoologia de Vertebrados foram responsáveis pelo material fotográfico do acervo zoológico do laboratório (Figura 1), bem como a construção de diversos conteúdos de divulgação científica, os quais foram desenvolvidos durante o ano. 


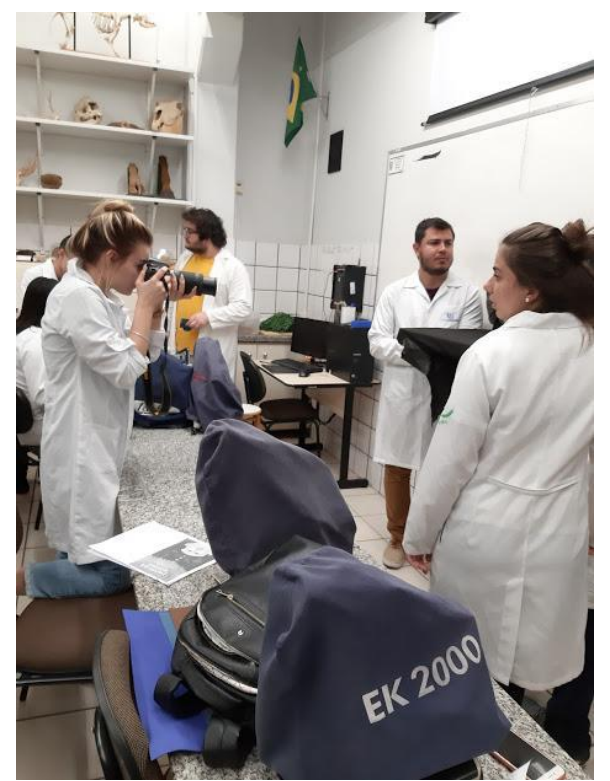

Figura 1: Ensaio fotográfico dos alunos na disciplina de Zoologia.

Fonte: Autoria própria (2019).

Após a pesquisa dos temas que seriam desenvolvidos pelos alunos, foram construídos diversos materiais de divulgação científica, com o intuito de difundir o conhecimento sobre os animais e a importância da preservação do ambiente de forma lúdica e descontraída. Assim, foi criado o site do museu durante $o$ ano de 2019 (Figura 2). O nome do museu e o layout foram escolhidos pelos alunos da disciplina em consenso.

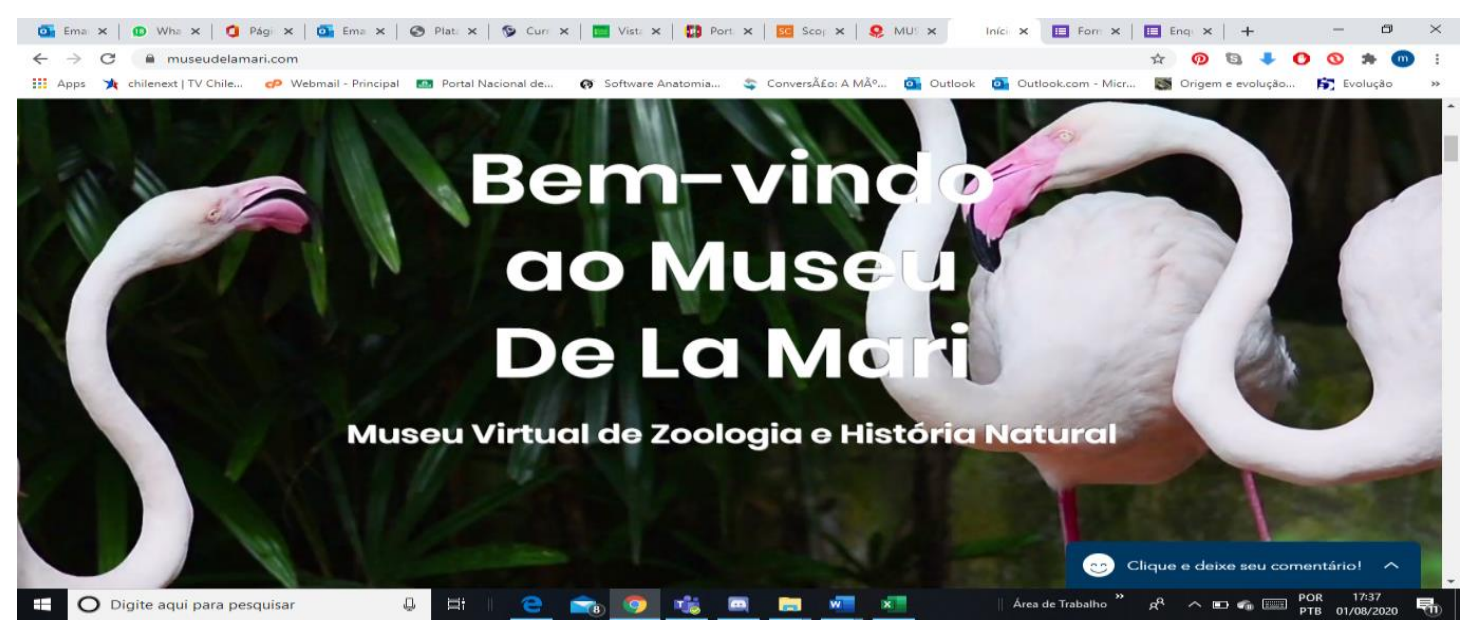

Figura 2: Página inicial do Museu virtual de Zoologia e História Natural.

Fonte: Autoria própria (2019). Disponível em: <www.museudelamari.com>.

Levando em consideração que "pesquisar é um processo coletivo de reconstrução, visando as transformações qualificadas de conhecimento e de práticas" (MORAES; RAMOS; GALIAZZI, 2004, p. 9), os alunos, por meio da pesquisa, realizam um questionamento reflexivo como forma de construção de 
novos argumentos, sendo que a comunicação crítica e a valorização da produção escrita ocorrem por meio da aprendizagem promovida. Desta forma, a construção de novos argumentos se dá ainda pela leitura crítica, pelo diálogo com os demais colegas e pela reflexão do objeto da pesquisa em questão.

Deste modo, o aluno se torna o protagonista da investigação e da construção do conhecimento, e o professor, o mediador. Assim, os temas referentes à zoologia, à preservação da biodiversidade e ao meio ambiente podem ser abordados de maneira interdisciplinar por meio da educação ambiental e não apenas de forma direcional. Os alunos compreendem os processos biológicos, refletem os objetos de aprendizagem e constroem materiais de divulgação científica, os quais podem ser utilizados na academia, no ensino fundamental e no ensino médio, beneficiando professores e alunos.

Observa-se ainda a relevância dos processos educacionais para a preservação do meio ambiente, tendo em vista que um maior acesso à informação influencia para a mobilização dos indivíduos. Em outras palavras, por meio da EA, os cidadãos se observam como atores sociais fundamentais na conquista da sustentabilidade. A educação, apesar de não ser o único caminho para alcançar o desenvolvimento sustentável, se torna um dos instrumentos mais significativos (AMBUSAIDI; AL WASHASI, 2016; NOUSHEEN et al., 2019).

Neste contexto, é imprescindível que a EA, vista como instrumento de transformação social, atinja tanto o ambiente escolar formal, quanto o extra escolar, a fim de alcançar também as faixas etárias que já não se encontram mais inseridas no cenário educacional (CARVALHO; DIAS, 2013).

Apesar de a EA ser relativamente antiga pela Constituição Federal em 1988, somente em 2012, entra nas Diretrizes Curriculares Nacionais (DCNs). No Art. 1을 a 2 ${ }^{\underline{a}}$ Resolução estabelece as Diretrizes Curriculares Nacionais para a Educação Ambiental, a serem observadas pelos sistemas de ensino e suas instituições de Educação Básica e de Educação Superior, orientando a implementação do determinado pela Constituição Federal e pela Lei oㅜ 9.795, de 1999, a qual dispõe sobre a EA e institui a Política Nacional de Educação Ambiental (PNEA) (BRASIL, 2012).

Para abordar práticas de Educação Ambiental, os alunos utilizaram a biodiversidade e o risco de extinção para realizar práticas inovadoras e mostrar a importância da defesa da vida e do meio ambiente e formar cidadãos cada vez mais comprometidos, como o que preconiza Jacobi (2003). Neste sentido, foi produzida uma cartilha, conforme apresentado na Figura 3. 


\section{Preservando o ambiente}

Cartilha sobre noçôes básicas de preservaçato e educaçä̀ ambiental.

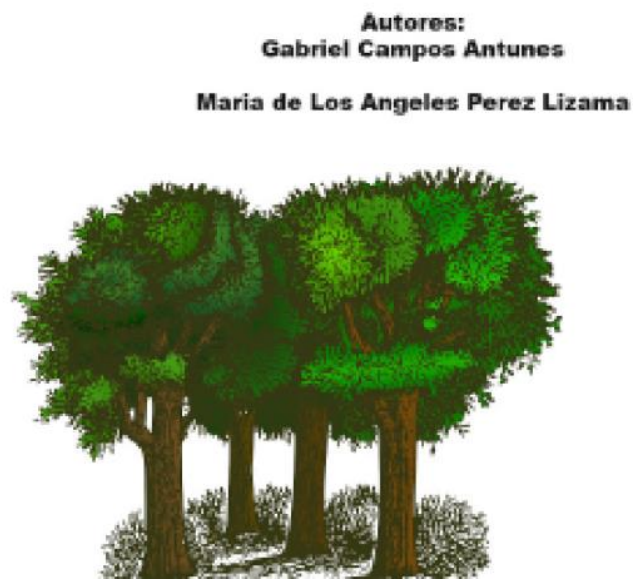

Figura 3: Cartilha sobre noções básicas de preservação e educação ambiental. Fonte: Antunes e Lizama (2019, não publicado). Disponível em: <www.museudelamari.com>.

Com o intuito de mostrar os resultados obtidos na construção do conhecimento adquirido pelos alunos, foi realizada uma exposição (Figura 4), na qual os diversos materiais produzidos foram expostos para os demais acadêmicos da IES e para alunos de escola do ensino fundamental e médio local.

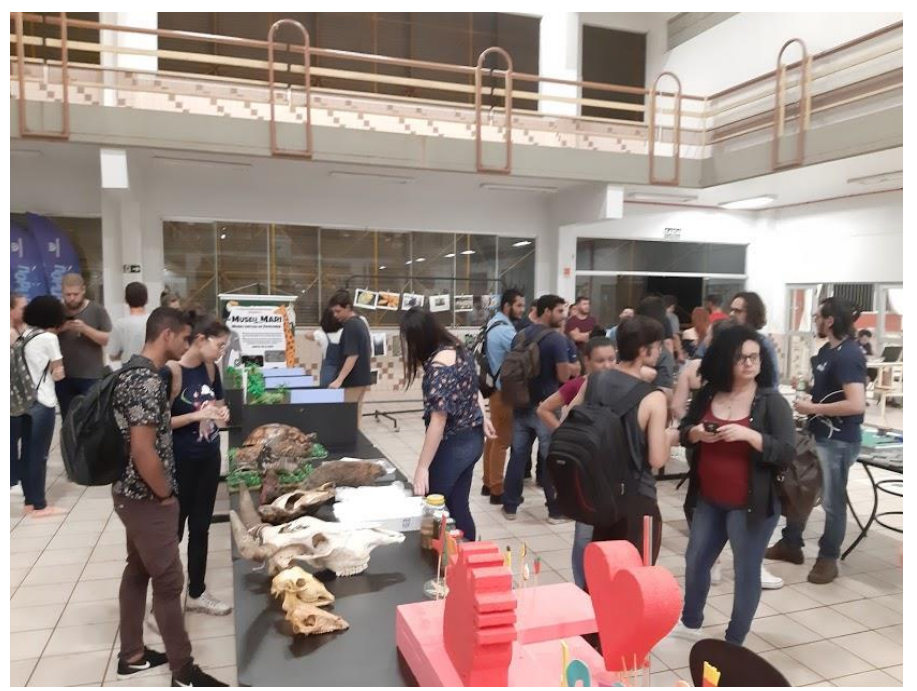

Figura 4: Exposição realizada com materiais de divulgação, a exposição fotográfica e demais produções desenvolvidas pelos graduandos. Fonte: Autoria própria (2019). 
A exposição dos materiais desenvolvidos e inseridos no museu virtual, bem como a exposição fotográfica (Figura 5), proporcionaram aos alunos crescimento e satisfação de construir e finalizar um projeto.
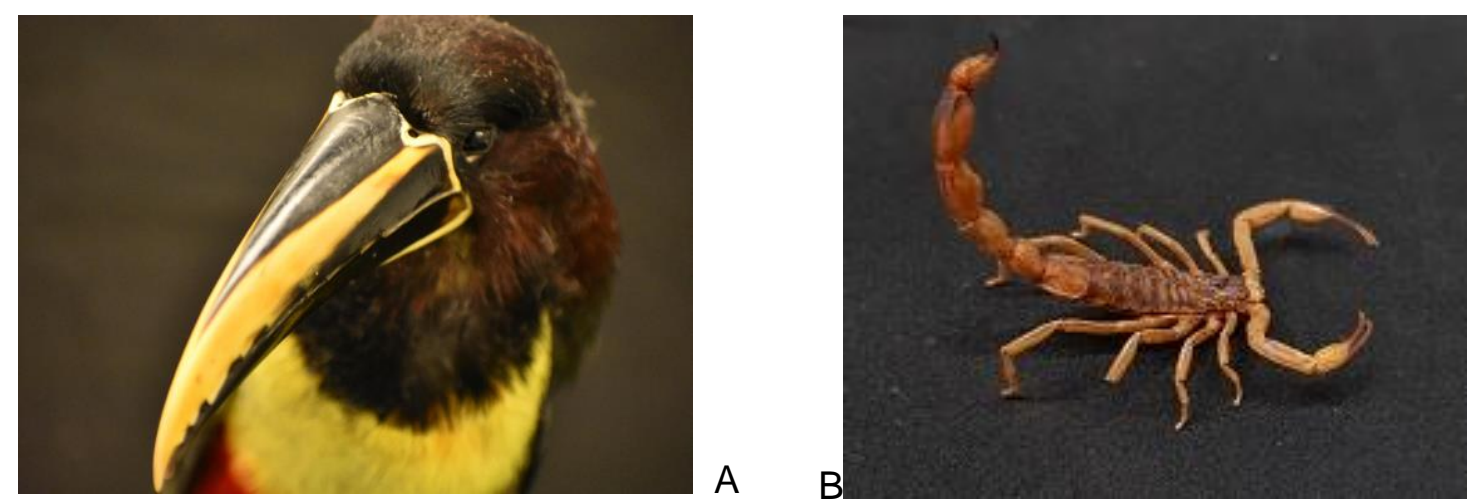

Figura 5: Acervo fotográfico utilizado no material de coleção e exposição.

A. Araçari-castanho (Pteroglossus castanotis). Fonte: Silva (2019); B. Escorpião marrom (Tityus serrulatus). Fonte: Azevedo (2019). Disponível em: <www.museudelamari.com>.

Após finalizado, os alunos responderam a um questionário, via Google Forms, sobre a participação na construção do museu virtual. Estes são alguns dos relatos espontâneos encaminhados pelos alunos em relação à participação na construção do museu virtual:

"Sem dúvidas foi maravilhoso fazer esse trabalho em equipe. Saber que esse projeto tem um pouquinho de cada aluno juntamente com a prof., sentimento de gratidão por podermos passar para outras pessoas nossos conhecimentos e mostrar o quão importante é nosso museu".

Relato da aluna J. M. M. concedido em 2019.

"O museu, além de demonstrar de forma mais prática essas matérias, é mais fácil de se entender os estudos em questão, sejam eles zoológicos ou das outras matérias abordadas pelo museu".

Relato do aluno G. C. A. concedido em 2019.

"É importante no aprendizado, pois ao ensinar os outros, você acaba aprendendo junto".

Relato do aluno E. B. concedido em 2019. 
meio eletrônico podem facilitar a divulgação de inúmeras informações aos usuários, e, neste sentido, podem auxiliar nas ações de educação ambiental, como a que foi realizada pelo Museu Virtual de la Mari.

\section{A função do Museu virtual em momento de Pandemia}

A Covid-19 submeteu os alunos ao isolamento social, promovendo efeitos negativos, como ansiedade, depressão, irritabilidade e expectativa (BROOKS et al., 2020). Além disso, a limitação de espaço e/ou de mobilidade, o medo da doença, do tédio, da limitação financeira e a possível perda de emprego também foram apontados por alguns autores como consequências da pandemia (SANTOS, 2020; SCHMIDT, 2020).

Observa-se ainda estudos que demonstram que jovens e adolescentes são dependentes das relações interpessoais para que ocorra um desenvolvimento sadio e relevante para a construção da personalidade do indivíduo adulto (FERREIRA et al., 2013). Neste contexto, revela-se a importância do museu virtual em tempos de pandemia.

Nestes tempos de pandemia, houve a necessidade de divulgar não somente o conhecimento científico, mas também divulgar o sentimento e a experiência que os acadêmicos e professores estavam passando. A partir da matéria intitulada Em tempos de Isolamento Social, a fotografia é uma terapia!, foi criada uma sessão de fotografias, a princípio, para os alunos e professores das Ciências Biológicas. Porém, vários acadêmicos de outros cursos tomaram conhecimento da sessão e quiseram participar. Eis aqui alguns relatos sem autoria:

"Alegria de ver minha sala participando".

Relato da aluna 1 concedido em 2019.

"Foi uma forma de me distrair da quarentena e esquecer o que estamos vivendo por um momento".

Relato da aluna 2 concedido em 2019.

"Sentimento de esperança de que conseguiremos ser fortes e passar por tudo isso unidos".

Relato da aluna 3 concedido em 2019.

"Compartilhar a experiência na quarentena".

Relato da aluna 4 concedido em 2019. 
Verifica-se que a tecnologia se tornou cada vez mais presente na vida de todos neste período de isolamento social em decorrência da Covid-19. Por esse motivo, a função do museu virtual, que era de divulgação científica e educação ambiental, passou a ter uma função social, que foi a de congregar os alunos e tornar esse momento mais leve.

Lizama (2020, on-line) descreve:

A fotografia, nestes tempos de isolamento, torna-se uma terapia, na qual, sem pretensão alguma de ser perfeito, ou utilizar as lentes perfeitas, pode-se dar margem a percepção do ambiente e ao lado artístico que existe em cada um...o olhar de cada "artista" projeta o belo, e descansa a mente, enquanto aguça os sentidos para os pequenos detalhes do cotidiano. Isso se torna uma terapia!

\section{Considerações finais}

As atividades promovidas para o desenvolvimento do museu permitiram que os alunos se enxergassem como atores na construção do conhecimento, tornando-os responsáveis e mais críticos.

Apesar de não ser possível verificar o real impacto das ações no comportamento ambiental dos alunos, os relatos mostram a valorização da transmissão de conhecimento para a comunidade. Neste sentido, o trabalho abordou tanto a educação ambiental formal, direcionada aos acadêmicos, quanto a não-formal, visto que o conhecimento científico se tornou mais acessível para a comunidade externa.

Além da divulgação de dados científicos sobre a biodiversidade, 0 museu tem a função de sensibilizar os indivíduos por meio da educação ambiental. Assim, acarreta um aprendizado interdisciplinar para a preservação do meio ambiente.

Ademais, o museu, indiretamente, teve a função de promover o bemestar dos alunos, não só da Biologia, mas de outros cursos. Por meio de registros fotográficos, os acadêmicos mostraram, através do próprio olhar, sentimentos positivos de compartilhar esse momento de incertezas.

\section{Agradecimentos}

Ao Instituto Cesumar de Ciência, Tecnologia e Inovação/ICETI, Maringá-PR - Brasil pela bolsa de Produtividade Pesquisa. Aos alunos da disciplina de Zoologia do curso de Ciências Biológicas que participaram deste projeto. 


\section{Referências}

AMBUSAIDI, A.; AL WASHAHI, M. Prospective Teachers' Perceptions about the Concept of Sustainable Development and Related Issues in Oman. Journal of Education for Sustainable Development, v. 10, n. 1, p. 3-19, 2016.

ANTUNES, G. C.; LIZAMA, M. A. P. Preservando o ambiente: cartilha sobre noções básicas de preservação e educação ambiental. Maringá, 2019. Disponível em: <www.museudelamari.com>. Acesso em: 17 dez. 2020.

AZEVEDO, F. M. Escorpião marrom (Tityus serrulatus). 1 fotografia. Disponível em:<http://www.museudelamari.com>. Acesso em: 22 ago. 2019.

BRASIL. Ministério da Educação. Resolução № 2, de 15 de junho de 2012. Diretrizes Curriculares Nacionais para a Educação Ambiental. Brasília: MEC, 2012. Disponível em: <http://portal.mec.gov.br/dmdocuments/rcp002 12.pdf>. Acesso em: 22 ago. 2020.

BROOKS, S.K.; WEBSTER, R.K.; SMITH, L.E.; WOODLAND, L.; WESSELY, S.; GREENBERG, N.; GIDEON, J.R. The psychological impact of quarantine and how to reduce it: rapid review of the evidence. Lancet, v. 395, p. 912-20, 2020.

CALDEIRA, P. da T. Museus. In: CAMPELO, B.S.; Caldeira, P. da T. (Org.). Introdução as fontes gerais de informação. Belo Horizonte: Autêntica Editora, 2005.

CARVALHO, R.V.; DIAS, R. O desenvolvimento de uma cultura ambiental corporativa através da educação ambiental. Revista em agronegócio e meio ambiente, v. 6, n. 3, 2013.

FERREIRA, D.; SANTOS, A.J.; RIBEIRO, O.; FREITAS, M.; CORREIA, J.V.; RUBIN, K. Isolamento social e sentimento de solidão em jovens adolescentes. Análise Psicológica, v. 2, n. XXXI, p.117-127, 2013.

HENRIQUES, R. Museus virtuais e cibermuseus: a internet e os museus. 2018. Disponível em: <https://globalherit.hypotheses.org/museu-afrodigitalestacao-portugal/museus-virtuais-e-cibermuseus-a-internet-e-os-museus $>$.

Acesso em: 15 jul. 2020.

JACOBI, P. R. Educação ambiental, cidadania e sustentabilidade. Cadernos de Pesquisa, n. 118, p. 189-205, 2003.

GANT, M.L.B. Artes, museos y nuevas tecnologías. Gijón: Trea, 2001.

INSTITUTO BRASILEIRO DE GEOGRAFIA E ESTATÍSTICA - IBGE. Censo demográfico. 2017. Disponível em: <https://cidades.ibge.gov.br/>. Acesso em: 30 jun. 2020.

LIZAMA, M.L.A.P. Em tempos de isolamento social, a fotografia é uma terapia! 2020. Disponível em: <www.museudelamari.com>. Acesso em: 30 jul. 2020. 
LONDON MUSEUM OF NATURAL HISTORY. Collections. Disponível em: $<$ https://www.nhm.ac.uk/our-science/collections.html>. Acesso em: 20 jun. 2020.

MORAES, R.; RAMOS, M.G.; GALIAZZI, M.C. Pesquisar e aprender em Educação Química: alguns pressupostos teóricos. Engenharia Ambiental, Espírito Santo do Pinhal, v. 1, n. 1, p. 57-64, jan./dez. 2004.

MUNIZ, R. A importância dos museus para a preservação da cultura. 2020. Disponível em: <https://www.hojeemdia.com.br/opini\%C3\%A3o/colunas/raquelmuniz-1.456804/import\%C3\%A2ncia-dos-museus-para-a-

preserva\%C3\%A7\%C3\%A3o-da-cultura-1.625767>. Acesso em: 20 mar. 2020.

NOUSHEEN, A. et al. Education for sustainable development (ESD): Effects of sustainability education on pre-service teachers' attitude towards sustainable development (SD). Journal of Cleaner Production, v. 239, p. 119537, 2019.

SANTOS, C.F. Reflections about the impact of the SARS-COV-2/COVID-19 pandemic on mental health. Brazilian Journal of Psychiatry, v. 42, n. 3, p. 329, 2020.

SCHMIDT, B.; CREPALDI, M.A.; BOLZE, S.D.A.; NEIVA-SILVA, L.; DEMENECH, L.M. Saúde mental e intervenções psicológicas diante da pandemia do novo coronavírus (COVID-19). Estudos de Psicologia, Campinas, v. 37, 2020.

SILVA, P. S. Araçari-castanho (Pteroglossus castanotis). 1 fotografia, color, 2019.

TEIXEIRA, R.S. Museu virtual: um novo olhar para a informação e comunicação na museologia. Perspectivas em Ciência da Informação, v. 19, n. 4, p. 226-238, out./dez. 2014. 